\title{
Osteomalacia as inaugural manifestation of Sjögren syndrome
}

\author{
Eya Cherif, Lamia Ben Hassine, Zouleikha Kaoueche, Narjess Khalfallah
}

Faculty of Medicine of Tunis, Department of Internal Medicine, Charles Nicolle's Hospital, Tunis El Manar, Tunis, Tunisia

\section{Correspondence to}

Dr Eya Cherif,

eyacherif@yahoo.fr
To cite: Cherif $\mathrm{E}$, Ben Hassine L, Kaoueche Z et al. BMJ Case Rep Published online: [please include Day Month Year] doi:10.1136/bcr-2013201052

\section{SUMMARY}

Osteomalacia is a relatively common condition, which is frequently underdiagnosed due to lack of clinical suspicion and non-specific symptoms. Osteomalacia can complicate tubulo-interstital nephritis. However, it occurs exceptionally as the first manifestation of Sjögren syndrome with renal involvement. It is a consequence of chronic metabolic acidosis and is associated with distal renal tubular acidosis. We report a 31-year-old woman hospitalised for a 1 year history of muscle weakness and joint and chest wall pains. Skeletal imagery showed Looser's zones in the left femoral neck. Investigations concluded to the diagnosis of primary Sjogren's syndrome.

\section{BACKGROUND}

Osteomalacia is a metabolic bone disease, which often presents with no specific presentations. The most common explanation is primary or secondary deficiency of vitamin D. Many disorders are associated with osteomalacia. The leading causes are nutritional and intestinal diseases. ${ }^{1}$ Occasionally, renal tubule disorder results in impaired vitamin $\mathrm{D}$ metabolism and can be complicated by osteomalacia.

Primary Sjögren syndrome (SS) is an autoimmune disorder affecting primarily exocrine glands. Tubulo-interstitial nephritis is a common extraglandular manifestation of SS. ${ }^{2}$ Most often it is a chronic tubulo-interstitial nephritis, generally asymptomatic but sometimes responsible of distal tubular acidosis. Osteomalacia has been reported rarely in the patient with Sjogren's disease with kidney involvement. ${ }^{3}$

\section{CASE PRESENTATION}

A 31-year-old woman, without any medical history, was hospitalised with 1 year history of muscle weakness in the lower extremities and chest wall pains. She had noticed eyes and mouth dryness for the past 4 years. The physical examination revealed that she was afebrile with normal vital signs. Her mobility was no restricted but she had difficulty in standing up with waddling gait. She was found to have pain in the left thigh without deformity and she had rib tenderness. There was no arthritis or neurological dysfunction. The remainder of the physical examination was normal. She did not have digestive symptoms. She reported no trauma or drug intake.

\section{INVESTIGATIONS}

The laboratory evaluation demonstrated decreases in serum calcium $(82 \mathrm{mg} / \mathrm{L})$ and phosphate $(22 \mathrm{mg} / \mathrm{L})$. The urinary calcium and phosphate excretion were within the normal range. Serum alkaline phosphatase was increased $(381 \mathrm{UI} / \mathrm{L})$. Others laboratory data were as follows: normal complete blood count, serum albumin of $43 \mathrm{~g} / \mathrm{dL}$, serum glucose of $5 \mathrm{mmol} /$ $\mathrm{L}$, sodium of $138 \mathrm{mmol} / \mathrm{L}$, potassium of $3 \mathrm{mmol} / \mathrm{L}$, chloride of $115 \mathrm{mmol} / \mathrm{L}$, and creatine of $0.90 \mathrm{mg} / \mathrm{dL}$. The serum bicarbonate was low at $13 \mathrm{mmol} / \mathrm{L}$. The urinary $\mathrm{pH}$ was 6.5 and the urinary anion gap was positive $(+26)$. The serum levels of creatine kinase and liver enzymes were within normal ranges. Thyroid function was normal. No glucose or proteins were found in the urine. The erythrocyte sedimentation rate was at $50 \mathrm{~mm} / \mathrm{h}$. The electrophoretic examination of the serum proteins showed a polyclonal hypergammaglobulinaemia at $34 \mathrm{~g} / \mathrm{L}$. C reactive protein was negative. Other biochemical findings were within normal limits.

The whole-body bone scintigraphy disclosed multiple increased tracer uptake on pelvis and the higher third of bilateral femur. Moreover, more diffuse hot spots appeared on rib cage, scapulae and spine. Radiographs were normal. The bone MRI centred on lumbar spine, pelvis and the upper end of femurs showed Looser's zones on the left femoral neck (figure 1).

This clinical, laboratory and radiological findings were strongly in favour of osteomalacia secondary to hypokalaemic hyperchloraemic metabolic acidosis. As the patient had symptoms of xerostomia and xerophthamia, a SS was suspected. The Schirmer's test was abnormal. Antinuclear

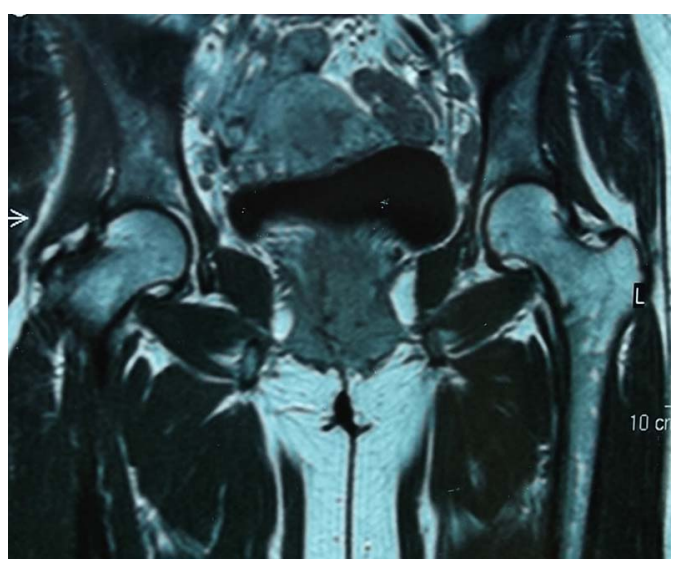

Figure 1 The bone MRI centred on the upper end of femurs showed Looser's zones on the left femoral neck. 
antibodies were present in a titre of 1/1280. Anti-SSA and anti-SSB were positive. A labial salivary gland biopsy revealed lymphocytic infiltration corresponding to Chisholm stage 4 lesions. The diagnosis of osteomalacia caused by renal involvement of SS was retained.

\section{TREATMENT}

The patient was treated with alkalinisation, vitamin $\mathrm{D}$, calcium, potassium supplements.

\section{OUTCOME AND FOLLOW-UP}

Her symptoms resolved over a 6 month period with normalisation of laboratory test abnormalities.

\section{DISCUSSION}

SS is a systemic autoimmune disease that primarily affects the salivary and lacrimal glands. However, this syndrome may manifest with extraglandular symptoms with widespread autoimmune manifestations. The systemic non-exocrine manifestations may include cutaneous, neurological, lung, renal or liver involvement. ${ }^{2}$ Distal renal tubular acidosis is an interesting and relatively common association with SS. Although subclinical renal inflammation can exist in more than $50 \%$ of patients, clinically significant kidney involvement occurs in approximately $5 \%$ of patients and is rarely presenting manifestation of the disease. $^{45}$ Most symptoms are related to secretory defect of distal tubules resulting from chronic interstitial nephritis. Hyperchloreamic metabolic acidosis, hypokalaemia, hypocalcaemia, nephrocalcinosis and nephrolithiasis are the common manifestations of renal tubular disorder. ${ }^{6}$ The bone can be involved during the chronic metabolic acidosis. In the case presented, a delay in diagnosis, as long as 4 years, may have contributed to the metabolic bone disease. The pathogenesis of this disorder has yet to be clarified. Acidosis, hypophosphataemia, vitamin D deficiency are responsible of a release of calcium from the bone which can progress slowly to osteomalacia and osteoporosis. ${ }^{7}$ Deformities and fractures have also been described in the patient with tubular acidosis secondary to $\mathrm{SS}^{8}$ As in our case, osteomalacia is exceptionally the first manifestation of SS. ${ }^{9}$ Bone pain and muscle weakness are often vague making diagnosis difficult. Looser's zone or fracture, which can be seen on by radiography, should be searched for in presence of localised pain. ${ }^{10}$ Bone scintigraphy is useful and usually shows enhanced radioisotope uptake in the lower spine, pelvis, lower extremities, ribs and shoulders. Biochemical investigations are characterised by a low serum calcium and phosphate with elevated serum alkaline phosphatase and low serum 25 -hydroxy vitamin D (25(OH)D). ${ }^{6}$
The treatment, including calcium supplementation, vitamin D and alkali therapy, leads to improvement of muscle tenderness and skeletal pain ${ }^{11}$

\section{Learning points}

- Management of patient with osteomalacia includes a vigorous search for underlying etiology.

- It is essential for all physicians to keep Sjogren's syndrome in the causes of osteomalacia, thus enabling its early diagnosis and better treatment.

- Sjogren's syndrome is a systemic autoimmune disease which may manifest with extraglandular symptoms, as renal tubular disorder.

\section{Competing interests None.}

Patient consent Obtained.

Provenance and peer review Not commissioned; externally peer reviewed.

\section{REFERENCES}

1 Arya V, Jain V. Osteomalacia: what the rheumatologist needs to know. Indian J Rheumatol 2007;2:17-22.

2 Venables P. Sjögren's syndrome. Best Pract Res Clin Rheumatol 2004;18:313-29.

3 Pal B, Griyths ID. Primary Sjögren's syndrome presenting as osteomalacia secondary to renal tubular acidosis. Br J Clin Pract 1998;42:436-8.

4 Eriksson $P$, Denneberg T, Larsson $L$, et al. Biochemical markers of renal disease in primary Sjögren's syndrome. Scand J Urol Nephrol 1995;29:383-92.

5 Goules A, Masouridi S, Tzioufas AG, et al. Clinically significant and biopsy-documented renal involvement in primary Sjögren syndrome. Medicine (Baltimore) 2000;79:241-9.

6 Basak R, Sharkawi K, Rahman M, et al. Distal renal tubular acidosis, hypokalemic paralysis, nephrocalcinosis. Primary hypothyroidism, growth retardation, osteomalacia and osteoporosis leading to pathological fracture: a case report. Oman Med J 2011;26:271-4

7 Fulop M, Mackay M. Renal tubular acidosis, Sjögren syndrome and bone disease. Arch Intern Med 2004;164:905-9.

8 Yang Y, Peng C, Sia S, et al. Acquired hypophosphatemia osteomalacia associated with Fanconi's syndrome in Sjögren's syndrome. Rheumatol Int 2007;27:593-7.

9 Hajjaj-Hassouni N, Guedira N, Lazrak N, et al. Osteomalacia as a presenting manifestation of Sjögren's syndrome. Rev Rhum Engl Ed 1995;62:529-32.

10 Tauvalea $S$, Bagneres $D$, Pasquali $R$, et al. An unusual cause of bone pain in a young woman. Rev Med Interne 2010;31:146-8.

11 Yamamoto S, Okada Y, Mori $\mathrm{H}$, et al. Successful treatment of osteomalacia caused by renal tubular acidosis associated with Sjögren's syndrome. Mod Rheumatol 2013:23:401-5

Copyright 2013 BMJ Publishing Group. All rights reserved. For permission to reuse any of this content visit http://group.bmj.com/group/rights-licensing/permissions.

BMJ Case Report Fellows may re-use this article for personal use and teaching without any further permission.

Become a Fellow of BMJ Case Reports today and you can:

- Submit as many cases as you like

- Enjoy fast sympathetic peer review and rapid publication of accepted articles

- Access all the published articles

- Re-use any of the published material for personal use and teaching without further permission

For information on Institutional Fellowships contact consortiasales@bmjgroup.com

Visit casereports.bmj.com for more articles like this and to become a Fellow 